\title{
Protein Kinase C Regulates the Cell Surface Activity of Endothelin-Converting Enzyme-1*
}

\author{
A. Ian Smith, ${ }^{1,4}$ Rebecca A. Lew, ${ }^{1}$ Walter G. Thomas, ${ }^{2}$ and Nathalie Tochon-Danguy ${ }^{3}$
}

\author{
(Accepted April 21, 2006; online publication May 19, 2006)
}

\begin{abstract}
The potent vasoconstrictor endothelin is a 21 amino acid peptide whose principal physiological function is to regulate vascular tone. The generation of endothelin is crucially dependent on the local presence and activity of endothelin converting enzyme-1 (ECE-1) expressed on the surface of vascular endothelial cells. In this study, we have shown in endothelial cells that the enzyme is phosphorylated, and that phosphorylation is increased by phorbol ester stimulation of protein kinase C (PKC). Furthermore, by monitoring specific ECE-1 activity on the surface of live cells, we also show that following PKC activation, enzyme activity is significantly increased at the cell surface, where it is positioned to catalyse the generation of active endothelin. We believe this novel finding is unprecedented for a peptide processing enzyme. Indeed, this new knowledge regarding the control of endothelin production by regulating ECE-1 activity at the cell surface opens up a new area of endothelin biology and will provide novel insights into the physiology and pathophysiology of endothelin and endothelin-associated diseases. In addition, the information generated in these studies may provide valuable new insights into potential extraand intracellular targets for the pharmacological and perhaps even therapeutic regulation of endothelin production and thus vascular tone.
\end{abstract}

KEY WORDS: endothelin converting enzyme 1 (ECE-1); endothelin; PKC; subcellular distribution.

\section{INTRODUCTION}

The endothelins (ET-1, ET-2 and ET-3) are a family of three closely related 21 amino acid peptides encoded by three distinct genes (Inoue et al., 1989).

* Australian Peptide Conference Issue.

${ }^{1}$ Peptide Biology Laboratory, Department of Biochemistry \& Molecular Biology, Monash University, Wellington Road, PO Box 13D, Clayton, VIC 3800, Australia.

${ }^{2}$ Molecular Endocrinology Laboratory, Baker Heart Research Institute, PO Box 6492, St Kilda Road Central, Melbourne, VIC 8008, Australia.

${ }^{3}$ Victoria College of Pharmacy, Royal Parade, Melbourne, VIC 3520 , Australia.

${ }^{4}$ Correspondence should be addressed to: A. Ian Smith, Peptide Biology Laboratory, Department of Biochemistry \& Molecular Biology, Monash University, Wellington Road, PO Box 13D, Clayton, VIC 3800, Australia. Tel.: +61-3-9905-1486; Fax: +613-9905-3726; e-mail: ian.smith@med.monash.edu.au.
Since their discovery (Yanagisawa et al., 1988), the endothelins (ET's) have attracted great scientific and clinical interest, which largely reflects their extremely potent and long-lasting vasoconstrictor effects (Sakurai and Goto, 1993), as well as their possible role(s) in tumour growth (Patel and Schrey, 1996) and endocrine function (Mansour et al., 1997). The vasoconstrictor action of endothelin is mediated via the $\mathrm{ET}_{\mathrm{A}}$ receptor located on the surface of vascular smooth muscle cells (Arai et al., 1990) and although the three peptides are expressed in many cell types, the most abundant isoform, ET-1, is almost exclusively expressed by vascular endothelial cells (Yanagisawa et al., 1988). The endothelins, unlike many other bioactive peptides, are stored as partially processed inactive precursors (big ET's) comprising 38-41 amino acids. Big ET is then cleaved upon secretion to the 21 amino acid bioactive ET by a highly specific 
endothelin converting enzyme (ECE) (Ohnaka et al., 1993). Therefore, the generation of bioactive ET-1 is critically dependent on the presence and activity of ECE on the surface of the cell.

The endothelin-converting enzyme-1 (ECE-1), is a highly glycosylated, type II membrane-associated neutral metalloendopeptidase (Shimada et al., 1994) and is highly specific, cleaving big ET between $\operatorname{Trp}^{21}$ and $\mathrm{Val} / \mathrm{Ile}^{22}$. Cloning studies have identified four ECE-1 isoforms (ECE-1a, ECE-1b, ECE-1c and ECE-1d) (Shimada et al., 1995; Valdenaire et al., 1999), all encoded by the same gene. Studies using mRNA protection analysis suggest that the ECE-1c isoform is dominant and is therefore the principal physiological regulator of ET production by endothelial cells (Takahashi et al., 1995; Schweizer et al., 1997). These ECE isoforms only differ in their cytoplasmic N-terminal tail, their selective expression reflecting the use of alternate promoters. Although all four isoforms have similar catalytic properties, the subtle $\mathrm{N}$-terminal variations appear to play an important role in differential subcellular trafficking (Schweizer et al., 1997; Jafri and Ergul, 2003)

A recent report by MacLeod et al. (2002) showed that ECE-1b, 1c \& 1d are constitutively phosphorylated at $\operatorname{Ser}^{18}$ and $\operatorname{Ser}^{20}$ (ECE-1c numbering; Fig. 1), most likely catalysed by casein kinase I. ECE-1a, which does not contain these residues, is not constitutively phosphorylated. We have now extended these studies to show that the endothelial isoform, ECE-1c, is not only constitutively phosphorylated as previously reported, but that the level of phosphorylation is markedly increased following protein kinase $\mathrm{C}$ (PKC) activation by phorbol esters. Furthermore, we show that following PKC activation, ECE-1c activity at the external surface of the endothelial cell plasma membrane is increased. These results perhaps suggest a novel mechanism for the rapid trafficking to and/or activation of a metallopeptidase at the cell surface, thus providing a physiological means to facilitate the increased production of endothelin, without the need for de novo synthesis of its precursor.

\section{MATERIAL AND METHODS}

\section{Antibody Production}

Polyclonal antibodies were raised in rabbits against the synthetic peptide, TYKRATLDEEDLC (conjugated to keyhole limpet haemocyanin through the C-terminal cysteine residue), corresponding to the amino acid stretch between residues 4 and 15 of the ECE-1c N-terminal cytoplasmic tail (Mimotopes, Clayton, Victoria, Australia) using standard procedures (Cooper and Paterson, 1997). Western analyses were performed using membranes prepared from immortalized EA.hy926 cells as described below. Specificity was determined by pre-absorption where the serum was incubated with $10 \mu \mathrm{g} / \mathrm{ml}$ of non-conjugated peptide.

\section{Gel Electrophoresis and Western Blotting}

Proteins were resolved by SDS-polyacrylamide gel electrophoresis ( 8 or $10 \%$ acrylamide) under reducing conditions. Resolved proteins were transferred to PVDF membrane, blocked overnight in $5 \% \mathrm{w} / \mathrm{v}$ dry milk, and incubated with anti-ECE antiserum (1:5000 in 5\% milk) for $1 \mathrm{~h}$. Proteins were detected using horseradish peroxidase conjugated sheep anti-rabbit $\operatorname{IgG}(1: 1000)$ and enhanced chemiluminescence detection system $\left(\mathrm{NEN}^{\mathrm{TM}} \mathrm{Life}\right.$ Science).

\section{Cell Culture}

Immortalized EA.hy926 cells were grown to $\sim 80 \%$ confluency in either 12-well culture plates (for phosphorylation studies) or 96-well microtitre plates (for cell-based ECE activity assays), as previously described (Norman et al., 2003).

\section{Phosphorylation and Immunoprecipitation of ECE-1c}

The procedure for phosphorylation and immunoprecipitation of ECE-1 was essentially as described by Thomas et al. (1998) for the angiotensin type 1 receptor. Briefly, EA.hy926 cells were serum starved for $16 \mathrm{~h}$, prior to incubation with $\left[{ }^{32} \mathrm{P}\right] \mathrm{Pi}(200 \mu \mathrm{Ci} / \mathrm{ml} ; \mathrm{ICN})$ in phosphate-free medium. In some instances, cells were stimulated by phorbol 12 -myristate 13 -acetate (PMA) $(2 \mu \mathrm{M}, 10 \mathrm{~min})$ at $37^{\circ} \mathrm{C}$, and when required, the PKC inhibitor bisindolmaleimide (BIM) $(2 \mu \mathrm{M})$, the CKII inhibitor apigenin $(80 \mu \mathrm{M})$, or PD98059, a MAP

\begin{tabular}{|c|c|c|c|c|c|c|c|}
\hline ECE-1a & & MPLQGLGL & QRNPFLQGKR & GPGLTSSPPL & LPPSLQVNFH & $\mathbf{S}^{39} \mathrm{PRS} G Q R C W A$ & ARTQVEKRLV... \\
\hline$E C E-1 b$ & MRGVWPPPVS & ALLSALGMS $\underline{\mathbf{T}}^{20}$ & YKRATLDEED & LVDSLSEGDA & YPNGLQVNFH & $\mathrm{S}^{51} \mathrm{PRSGQRCWA}$ & ARTQVEKR $L V \ldots$ \\
\hline$E C E-1 C$ & & $\operatorname{MMS} \underline{T^{4}}$ & YKRATLDEED & LVDSLSEGDA & YPNGLQVNEH & $\mathrm{S}^{35} \mathrm{PRSGQRCWA}$ & ARTQVEKR $L V . .$. \\
\hline$E C E-1 d$ & MEALRES & VLHLALQMS $\frac{\mathbf{T}^{17}}{\star}$ & $\frac{\text { YKRATLDEED }}{\hat{\Lambda}}$ & $\begin{array}{c}\text { LVDSLSEGDA } \\
\wedge \hat{\wedge}\end{array}$ & YPNGLQVNEH & $\begin{array}{l}\mathrm{S}^{48} \mathrm{PRS} \mathrm{SQRCWA} \\
\star \quad \cdot\end{array}$ & $\begin{array}{l}\mathrm{ART} Q V E K R L V \ldots \\
\Lambda\end{array}$ \\
\hline
\end{tabular}

Fig. 1. Putative phosphorylation sites in the cytoplasmic domains of the four ECE-1 isoforms. The putative phosphorylation site(s) of PKC are marked by $*$, of MAP kinase by $\bullet$ and of casein kinase II by $\wedge$. The start of the transmembrane domain is represented by italic characters, while the sequence used to raise antisera is underlined. Searches were performed using ANGIS and Swiss PROT data bases. 
kinase inhibitor $(20 \mu \mathrm{M})$, was added for $30-120 \mathrm{~min}$ at $37^{\circ} \mathrm{C}$ prior to PMA stimulation. Cells were lysed in the presence of phosphatase and protease inhibitors as described (Thomas et al., 1998) and after pre-clearing with Protein-A agarose, lysates were incubated overnight $\left(4^{\circ} \mathrm{C}\right)$ with $20 \mu \mathrm{l}$ of Protein A-agarose and $2 \mu \mathrm{l}$ of anti-ECE- 1 antiserum. Washed immuno-precipitates were resolved onto $8 \%$ SDS-PAGE, and dried gels were exposed overnight against a Fujitype BAS-IIIs PhosphorImaging plate. The plates were subsequently read in a FUJIX Bio-imaging Analyser BAS 1000 and the data analysed using MacBAS version 1.0 software. Quantitative data derived from phosphorimage analysis were normalized relative to unstimulated cells. Results were compared using a Student's $t$-test, and $p$ values $<0.05$ were considered significant.

\section{Cell-based Quenched Fluorescent Substrate Assay}

EA.hy926 cells grown in 96-well microtiter plates were washed with Opti-MEM (Invitrogen Australia, Mt. Waverley, Victoria), before adding $180 \mu \mathrm{l}$ fresh Opti-MEM with or without $10 \mu \mathrm{M}$ or $50 \mu \mathrm{M}$ thiorphan (Auspep, Parkville, Victoria) to inhibit neutral endopeptidase (NEP), or $10 \mu \mathrm{M}$ phosphoramidon (Sigma) to inhibit both NEP and ECE-1. Following pre-incubation at $37^{\circ} \mathrm{C}$ for $30 \mathrm{~min}$, a bradykinin-based quenched fluorescent substrate (QFS), (7-methoxycoumarin-4-yl)acetyl-Arg-Pro-Pro-Gly-Phe-SerAla-Phe- Lys(2, 4-dinitrophenyl) (custom synthesized by Auspep; Johnson and Ahn, 2000), was added to a final concentration of $40 \mu \mathrm{M}$. Fluorescence generated by cleavage of the QFS was continuously monitored $\left(\lambda_{\mathrm{ex}}=320 \mathrm{~nm}, \lambda_{\mathrm{em}}=405 \mathrm{~nm}\right)$ in a FLUOStar Optima plate reader (BMG LabTech, Offenburg, Germany) maintained at $37^{\circ} \mathrm{C}$. Each group (control, $10 \mu \mathrm{M}$ thiorphan, $50 \mu \mathrm{M}$ thiorphan, or phosphoramidon) consisted of 3 wells. In a second experiment, cells were pre-incubated in $10 \mu \mathrm{M}$ thiorphan prior to addition of QFS. At $30 \mathrm{~min}$ following QFS addition, PMA $(2 \mu \mathrm{M}$ final concentration) or its vehicle (Opti-MEM) was added to each well using the automated injector function of the plate reader $(10 \mu \mathrm{l}$ volume/well); fluorescence was monitored for a further $90 \mathrm{~min}$. Each group (vehicle or PMA injection) consisted of 9 wells.

\section{RESULTS}

\section{Endothelial ECE-1 is Phosphorylated}

The amino acid sequence of the N-terminal cytoplasmic tail of ECE-1 contains PKC, CKII and MAPK consensus phosphorylation motifs (Fig. 1), suggesting that the enzyme may be a kinase substrate in mammalian cells. To determine if ECE-1 could be phosphorylated, anti-ECE-1 antibodies were generated and used to immunoprecipitate $\left[{ }^{32} \mathrm{P}\right]$-labelled ECE-1 from endothelial cells. Western blotting of membranes prepared from the cells demonstrated recognition of ECE-1 by our antiserum, as an approximately $120 \mathrm{kDa}$ protein was detected in endothelial cells (data not shown). This band was not detected using pre-immune serum or ECE-1c antiserum pre-absorbed with the synthetic peptide (data
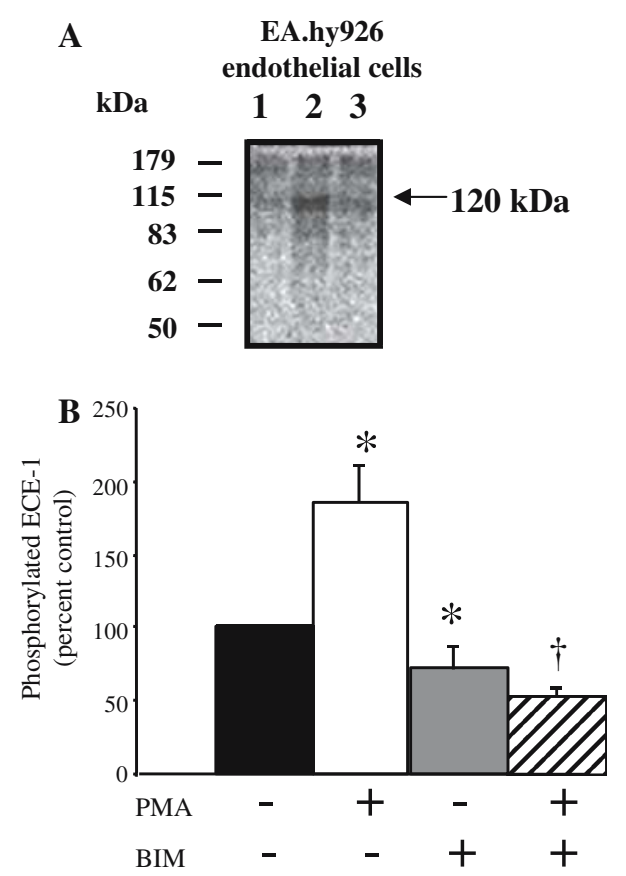

Fig. 2. Phosphorylation of ECE-1. Panel A: Phosphorimage of phosphorylated ECE-1. Cell lysates from EA.hy926 endothelial cells incubated in $\left.{ }^{32} \mathrm{P}\right] \mathrm{Pi}$ were immunoprecipitated using anti-ECE1 antibody, and resolved by SDS-PAGE prior to detection of radioactivity by phosphorimage analysis. Cells were either unstimulated (lane 1), stimulated with $2 \mu \mathrm{M}$ PMA (lane 2), or with $200 \mu \mathrm{M}$ dibutyryl cAMP (lane 3). Panel B: Effect of PMA and BIM on ECE-1 phosphorylation. EA.hy926 cells were incubated with $\left[{ }^{32} \mathrm{P}\right] \mathrm{Pi}$ in the presence or absence of $2 \mu \mathrm{M}$ PMA $(10 \mathrm{~min})$ or $2 \mu \mathrm{M}$ BIM (30 min) or both prior to immunoprecipitation and phosphorimage analysis as described and shown in panel A. Results were expressed as percentage change compared with the unstimulated control for each experiment. Data are means \pm SEM from 11 experiments (PMA stimulation) and 5 experiments (BIM treatment). ${ }^{*} p<0.05$ vs. basal; $\uparrow p<0.05$ vs. PMA-treated.

not shown). Our antiserum could also effectively immunoprecipitate ECE-1, and phosphorylated ECE-1 protein was detected in endothelial cells (Fig. 2A).

\section{PKC Activation Increases ECE-1 Phosphorylation}

In endothelial cells, the phosphorylation of ECE-1 was increased (50-100\% above basal levels) when cells were treated with the PKC activator, PMA (Fig. 2). In contrast, di-butyryl cAMP did not influence ECE-1 phosphorylation in the endothelial cells (Fig. 2A, lane 3), consistent with the absence of classical putative PKA phosphorylation sites in ECE1. As expected, inhibition of PKC with BIM blocked the effect of PMA treatment on ECE-1 phosphorylation (Fig. 2B); interestingly, basal phosphorylation was also reduced, but not completely blocked, by 
$\mathrm{BIM}$, suggesting a partial involvement of $\mathrm{PKC}$ in constitutive levels of ECE phosphorylation. Neither the CKII inhibitor apigenin, nor the MAP kinase inhibitor PD98059 significantly reduced basal or PMA-induced phosphorylation of ECE-1 (data not shown).

\section{Extracellular ECE-1 Catalytic Activity}

The efficient cleavage of a bradykinin-based ECE-1 quenched fluorescent substrate by intact EA.hy926 endothelial cells was partially inhibited by the neutral endopeptidase inhibitor thiorphan and completely blocked by inhibition of both NEP and ECE-1 by phosphoramidon (Fig. 3A). Addition of the phorbol
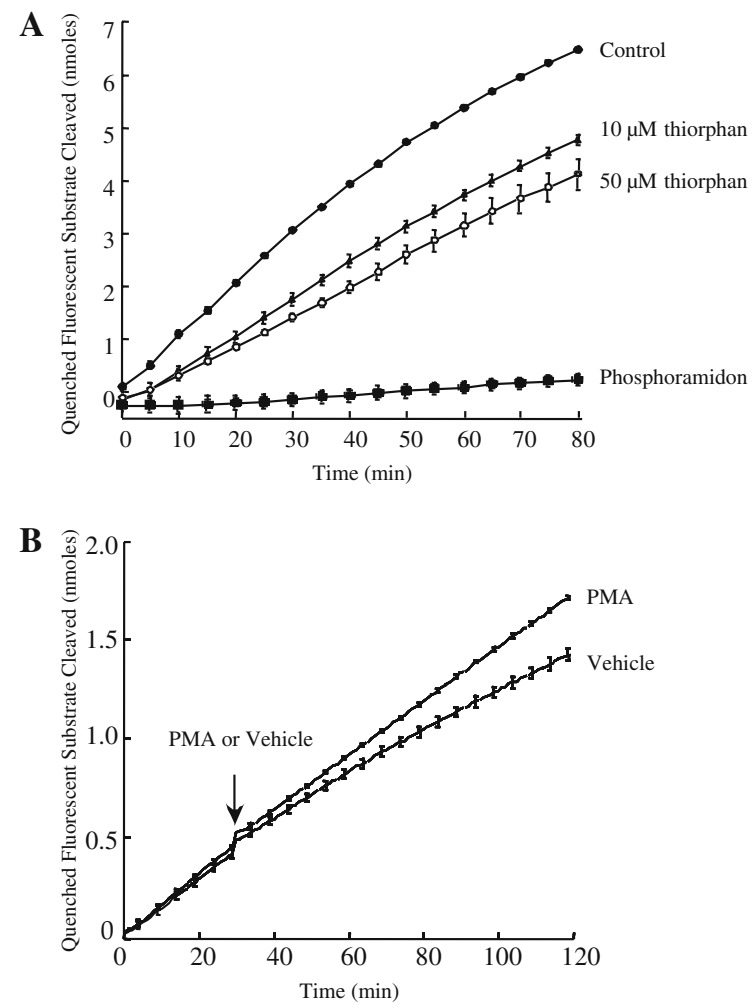

Fig. 3. Cleavage of ECE-1 quenched fluorescent substrate (QFS) by EAhy926 endothelial cells in culture. Panel A: Endothelial cells grown in 96-well microtiter plates were incubated with an ECE-1 QFS in the absence or presence of the NEP inhibitor thiorphan (10 or $50 \mu \mathrm{M})$ or the NEP/ECE inhibitor phosphoramidon $(10 \mu \mathrm{M})$ within a thermostatted plate reader, and fluorescence continuously monitored. Shown are the results depicting the mean nmoles of QFS cleaved ( $n=3$ per group, \pm s.e.m.) for every fifth fluorescence determination. Panel B: Treatment with PMA increases cell-surface ECE-1 activity. Cells grown in 96-well plates were preincubated for $30 \mathrm{~min}$ with $10 \mu \mathrm{M}$ thiorphan prior to addition of ECE-1 QFS. After a further $30 \mathrm{~min}, 10 \mu \mathrm{l}$ vehicle or PMA (40 $\mu \mathrm{M}$ stock) was added to each well. Shown are the results depicting the mean nmoles of QFS cleaved ( $n=8$ per group, \pm s.e.m.) for every fifth fluorescence determination. ester PMA resulted in an increase in the rate of QFS cleavage relative to the vehicle control (Fig. 3B), suggesting a greater ECE-like catalytic capacity at the cell surface as a consequence of PMA addition.

\section{DISCUSSION}

The only differences between the four isoforms of human ECE-1 lie in the short N-terminal cytoplasmic tail region (Fig. 1); however, and importantly in the context of the current study, it is these differences that influence the subcellular distribution of ECE (Cailler et al., 1999; Muller et al., 2003). Experiments using site-directed mutagenesis (alanine scans through the tails of the ECE isoforms) have shown that, as in the case of some other trafficked membrane proteins such as G-protein coupled receptors, di-leucine and/or Leu-Val internalization/retention motifs are likely involved in this trafficking event (Cailler et al., 1999). Interestingly, the ECE inhibitor phosphoramidon has been shown to actually induce the internalization of ECE in a dose-dependent manner (Barnes et al., 1996). Taken together, these findings provide evidence for an active pathway(s) for transferring ECE to and from the cell surface. Experimental evidence using cell-impermeable inhibitors as well as the conversion of exogenous big ET (Kwan et al., 1998; Loffler, 2000) suggests that ECE action occurs primarily at the endothelial cell surface and that a molecular mechanism exists to regulate ECE trafficking within the endothelial cell. Given that we have previously shown that the angiotensin $\mathrm{AT}_{1}$ receptor is internalized following agonist activation, a process dependent on specific phosphorylation events in the cytoplasmic tail of the receptor (Kule et al., 2004), we tested the hypothesis that ECE can be phosphorylated and that phosphorylation may impact on ECE activity at the cell surface. In this context, examination of the cytoplasmic tails of the ECE isoforms reveals a number of putative kinase recognition sites (Fig. 1). Indeed, our studies show that immunoreactive ECE-1 natively expressed in endothelial cells (EA.hy926) is constitutively phosphorylated (Fig. 2). In the same study we have shown that stimulation of PKC by the phorbol ester PMA increases the level of phosphorylation in endothelial cells (Fig. 2). Furthermore, these increases can be blocked by prior treatment with the PKC inhibitor BIM (Fig. 2), but not by inhibitors of casein kinase II or PKA (data not shown).

Given that ECE-1c expression has been reported both within the cell and at the cell surface, we 
hypothesized that the phosphorylation observed following PKC activation may serve as a signal for the trafficking of ECE-1c in endothelial cells. As phosphorylation is known to regulate internalization of other cell surface proteins, we embarked on a study designed to identify any changes in endothelial ECE-1 activity at the cell surface following PKC activation. We therefore examined the capacity of intact EA.hy926 endothelial cells to hydrolyse the ECE quenched fluorescent substrate both in the absence and presence of PMA. The addition of PMA significantly increased the rate of hydrolysis (Fig. 3b), suggesting increased catalytic capacity at the cell surface and consistent with migration of ECE to the cell surface. However, definitive cell surface labeling studies (beyond the scope of the current study) would be needed to unequivocally differentiate whether it is catalytic activation and/or selective trafficking to the cell surface following PKC mediated phosphorylation that leads to enhanced cell surface ECE activity.

\section{CONCLUDING REMARKS}

The results of the studies outlined above show for the first time that the phosphorylation of ECE is regulated and that following phosphorylation ECE catalytic activity is increased at the cell surface where it can catalyse the generation of active endothelin. This novel finding is, we believe, unprecedented for a peptide-processing enzyme. Knowledge about the control of endothelin production by regulating ECE-1 distribution opens up a new area of endothelin biology and will provide novel insights into the physiology and pathophysiology of endothelin and endothelinassociated diseases. Finally, the information generated in these studies may also provide valuable new information about potential extra- and intracellular targets for the pharmacological and perhaps therapeutic regulation of endothelin production.

\section{REFERENCES}

Arai, H., Hori, S., Aramori, I., Ohkubo, H. and Nakanishi, S.: 1990, Nature 348, 730-732.

Barnes, K., Shimada, K., Takahashi, M., Tanzawa, K. and Turner, A. J.: 1996, J. Cell Sci. 109, 919-928.
Cailler, F., Zappulla, J. P., Boileau, G. and Crine, P.: 1999, Biochem. J. 341, 119-126.

Cooper, H. and Paterson, Y.: 1997, in F. Ausubel, R. Brent, R. Kingston, D. Moore, J. Seidman, J. Smith, K. Struhl (eds.), Current Protocols in Molecular Biology Vol. 3. John Wiley \& Sons, Inc, New York, pp. 11.12.1-11.12.9.

Inoue, A., Yanagisawa, M., Kimura, S., Kasuya, Y., Miyauchi, T., Goto, K. and Masaki, T.: 1989, Proc. Natl. Acad. Sci. USA 86, 2863-2867.

Jafri, F. and Ergul, A.: 2003, Arterioscler. Thromb. Vasc. Biol. 23, 2192-2196.

Johnson, G. D. and Ahn, K.: 2000, Anal Biochem. 286, 112-118.

Kule, C. E., Karoor, V., Day, J. N., Thomas, W. G., Baker, K. M., Dinh, D., Acker, K. A. and Booz, G. W.: 2004, Regul. Pept. 120, 141-148.

Kwan, A. L, Bavbek, M., Jeng, A. Y., Toyoda, T., Kassell, N. F. and Lee, K. S.: 1998, J. Cardiovasc. Pharmacol. 31(Suppl 1), S320-S322.

Loffler, B. M.: 2000, J. Cardiovasc. Pharmacol. 35(Suppl. 2), S79S82.

MacLeod, K. J., Husain, R. D., Gage, D. A. and Ahn, K.: 2002, J. Biol. Chem. 277, 46355-46363.

Mansour, V. M, Clarke, I. J. and Smith, A. I.: 1997, Regul. Pept. $70,55-65$.

Muller, L., Barret, A., Etienne, E., Meidan, R., Valdenaire, O., Corvol, P. and Tougard, C: 2003, J. Biol. Chem. 278, 545555.

Norman, M. U., Reeve, S. B., Dive, V., Smith, A. I. and Lew, R. A.: 2003, Am. J. Physiol. Heart Circ. Physiol. 284, H1978H1984.

Ohnaka, K., Takayanagi, R., Nishikawa, M., Haji, M. and Nawata, H.: 1993, J. Biol. Chem. 268, 26759-26766.

Patel, K. V. and Schrey, M. P.: 1996, Cancer Treat. Res. 83, 369394.

Sakurai, T. and Goto, K.: 1993, Drugs B46, 795-804.

Schweizer, A., Valdenaire, O., Nelbock, P., Deuschle, U., Dumas Milne Edwards, J. B., Stumpf, J. G. and Loffler, B. M.: 1997, Biochem. J. 328, 871-877.

Shimada, K., Takahashi, M. and Tanzawa, K.: 1994, J. Biol. Chem. 269, 18275-18278.

Shimada, K., Takahashi, M., Ikeda, M. and Tanzawa, K.: 1995, FEBS Lett. 371, 140-144.

Takahashi, M., Fukuda, K., Shimada, K., Barnes, K., Turner, A. J., Ikeda, M., Koike, H., Yamamoto, Y. and Tanzawa, K.: 1995, Biochem. J. 311, 657-665.

Thomas, W. G., Motel, T. J., Kule, C. E., Karoor, V. and Baker, K. M.: 1998, Mol. Endocrinol. 12, 1513-1524.

Valdenaire, O., Lepailleur-Enouf, D., Egidy, G., Thouard, A., Barret, A., Vranckx, R., Tougard, C. and Michel, J. B.: 1999, Eur. J. Biochem. 264, 341-349.

Yanagisawa, M., Kurihara, H., Kimura, S., Tomobe, Y., Kobayashi, M., Mitsui, Y., Yazaki, Y., Goto, K. and Masaki, T.: 1988, Nature 332, 411-415. 